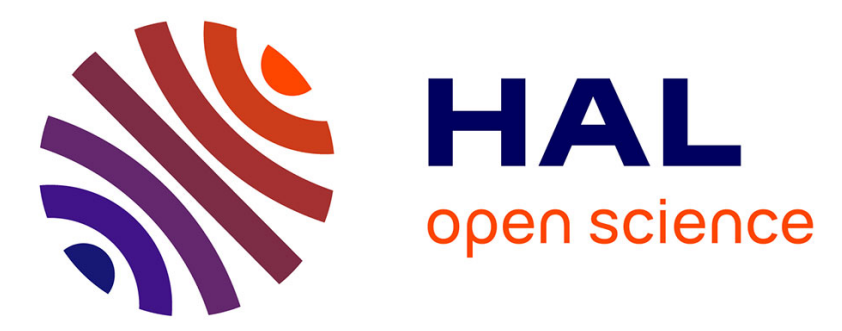

\title{
Vibro-Acoustic Optimization of a Permanent Magnet Synchronous Machine Using The Experimental Design Method
}

Stephane Vivier, A. Ait-Hammouda, Michel Hecquet, B. Napame, Pascal Brochet, Andry Randria

\section{To cite this version:}

Stephane Vivier, A. Ait-Hammouda, Michel Hecquet, B. Napame, Pascal Brochet, et al.. VibroAcoustic Optimization of a Permanent Magnet Synchronous Machine Using The Experimental Design Method. SpringerBriefs in Applied Sciences and Technology, 2006. hal-01731166

\author{
HAL Id: hal-01731166 \\ https://hal.science/hal-01731166
}

Submitted on 13 Mar 2018

HAL is a multi-disciplinary open access archive for the deposit and dissemination of scientific research documents, whether they are published or not. The documents may come from teaching and research institutions in France or abroad, or from public or private research centers.
L'archive ouverte pluridisciplinaire HAL, est destinée au dépôt et à la diffusion de documents scientifiques de niveau recherche, publiés ou non, émanant des établissements d'enseignement et de recherche français ou étrangers, des laboratoires publics ou privés. 


\title{
Vibro-Acoustic Optimization of a Permanent Magnet Synchronous Machine Using The Experimental Design Method
}

\author{
S. Vivier, A. Ait-Hammouda, M. Hecquet, B. Napame, P. Brochet, A. Randria* \\ L2EP - Ecole Centrale de LILLE \\ Ecole Centrale de Lille, Cité scientifique, B.P. 48, 59651 Villeneuve D’Ascq Cedex, France \\ *Alstom - ORNANS \\ stephane.vivier@ec-lille.fr, michel.hecquet@ec-lille.fr
}

\begin{abstract}
The aim of this paper is to use an analytical multiphysical model - electromagnetic, mechanic and acoustic - in order to predict the electromagnetic noise of a permanent magnet synchronous machine (P.M.S.M.). Afterwards, the experimental design method, with a particular design : "trellis design", is used to build response surfaces of the noise with respect to the main factors. These surfaces can be used to find the optimal design or more simply, to avoid unacceptable designs of the machine, in term of noise for a variable speed application.
\end{abstract}

\section{INTRODUCTION}

The majority of the electric machines operate at variable speed. In most of cases, it involves a generation of noise and vibrations, for a given speed and frequency.

For industries of manufacture, but also with the increasingly rigorous European standards, it is necessary to take into account the noise and the vibrations from the design stage.

A classical method used to study electromagnetic phenomena is the finite element method (F.E.M.) in magneto-dynamics including the coupling with electrical circuits. However, in the case of strong coupling, taking into account the electromagnetic, vibro-acoustic, and thermic models in the same time would need a considerable computing effort. This would make the structure optimization practically impossible. In order to solve this problem, an analytical approach is considered instead.

The aim of this work is to develop and use an analytical multi-physical model - electromagnetic, mechanic and acoustic - of a synchronous machine with permanent magnets. The complete model is coded using the dataprocessing tool MATLAB ${ }^{\circledR}$, making possible the determination of fast and simple prediction models of the acoustic noise.

In order to reduce noises and vibrations, two main ways can be considered: by the control of the machine excitation [1], or by modifying the system structure. In this work, only the second solution is explored.

Three models are presented : electromagnetic, mechanical of vibration and acoustic. For each of them, comparisons with F.E.M. and experiments have been made.

Lastly, a study of sensitivity is presented in order to deduce the influential - or significant - factors on the noise. For that, the technique of the experimental designs is used. More particularly, the modelling of the noise will be achieved thanks to the new "trellis" designs.
Several response surfaces are given; they represent the noise according to influential factors, with respect to different speeds of the machine.

These surfaces are useful to deduce the parts of the design space to avoid.

\section{PRESENTATION OF THE SYNCHRONOUS MACHINE}

This machine is composed of eight rotor poles and 48 stator slots.

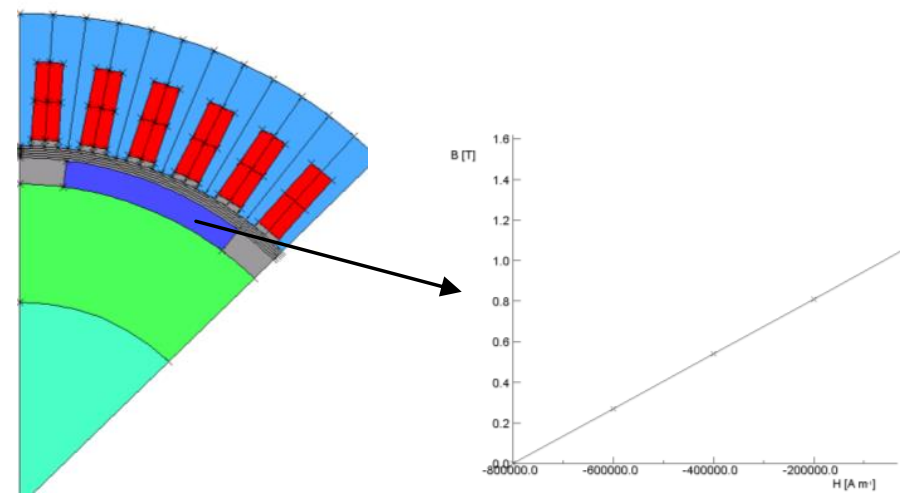

Figure 1. 1/8 of synchronous machine with magnet characteristic

The power of this machine is about $250 \mathrm{~kW}$.

\section{ANALYTICAL MODELS}

The vibration analysis of electrical machines is a rather old problem. During the 40s and 50s, it was deeply studied by various researchers [2] to [5]. Vibrations of electromechanical systems are due to excitation forces. Some of them have a magnetic origin. Other sources of vibrations, such as aerodynamic conditions, bearings, etc., will not be considered in this paper.

An analytical model, considering electromagnetic phenomena, mechanical vibrations and acoustic noises, was developed to take into account the overall noise produced by a variable induction in the air-gap [6] to [9] and by forces applied to the various structures.

\section{1) Electromagnetic model}

It is assumed that forces in the air gap of the machine are the main mechanical excitation. To characterize induction in the air-gap, the proposed method is based on 
the calculation of the air-gap permeance $\left(P_{e}\right)$ and the magnetomotive force ( $m m f)$ [6], [7] and [8]. To establish the analytical expression of the permeance, some assumptions are made :

- the magnetic circuit has a high permeability and a linear characteristic,

- the tangential component of the air-gap flux density is negligible relative to the radial component.

Results are given in reference [10] and just a comparison is recalled by the following figures.

Using the finite element software OPERA-2D [11], the air-gap induction created by the magnet rotor as a function of space and time has been also calculated. In figure 2, a comparison on induction wave shapes versus the angle is presented. The comparison results are very satisfactory, the induction distribution and the harmonic values determined analytically are validated numerically, as shown in ref. [6] and [12].
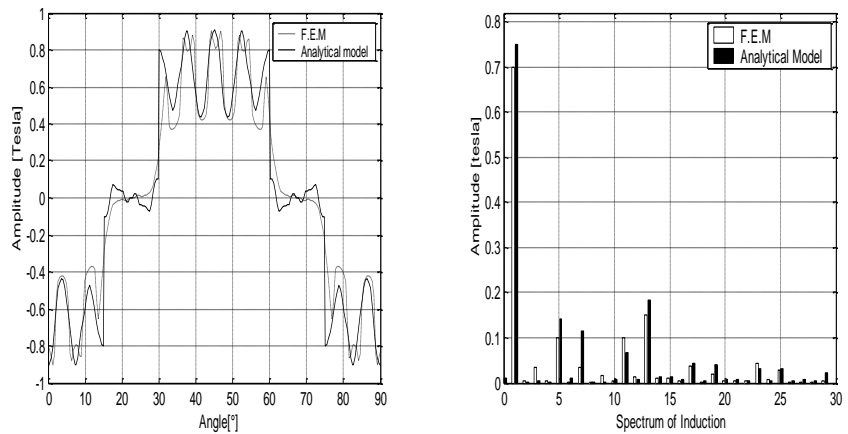

Figure 2. Comparison of the form induction and FFT

The $\mathrm{fft}$ of the radial forces versus time $(\mathrm{t})$ and angle $(\theta)$ is presented below in figure 3 :

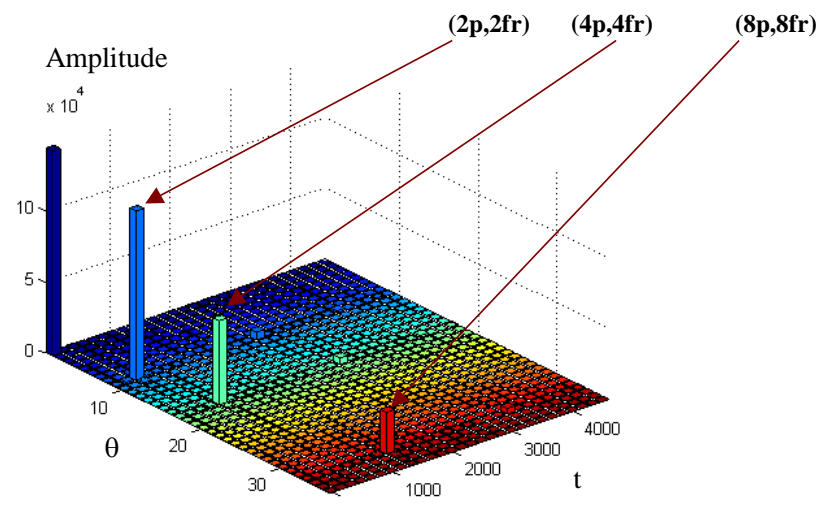

Figure 3. FFT 2D of radial force $(f r=p \times N)$

\section{2) Vibratory model}

Vibrations are the consequence of the excitation of the mechanical system by electromagnetic forces. Once the forces applied to the stator have been determined, the study of vibrations is possible. They correspond to the deformations whose amplitudes have to be calculated. For that purpose, some parameters have to be determined :

- the damping,

- the mode shapes and resonance frequencies for each mode.
For the damping coefficient, we have used the experimental measurements and the software PULSE [13] to determine the resonance frequencies, the mode shapes and the damping. For example, figure 4, some results are detailed:

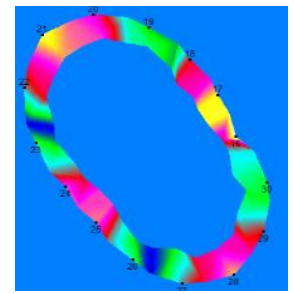

Mode 2 $376 \mathrm{~Hz}(3.32 \%)$

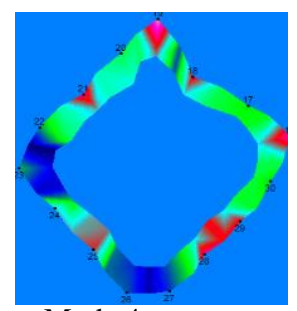

Mode 4

$1720 \mathrm{~Hz}(1.31 \%)$

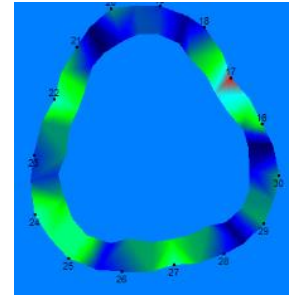

Mode 3

$1004 \mathrm{~Hz}(1.44 \%)$

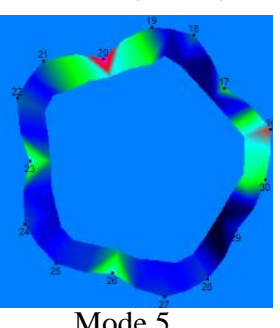

$2870 \mathrm{~Hz}(1.54 \%)$
Figure 4. Mode shape, resonance frequencies with (damping coef.) obtained by measurements

The studied analytical model takes into account the yoke, the frame, the teeth and the winding. The self vibration modes of the stator structure are determined, in various configurations: yoke only, yoke + teeth, yoke + teeth + carcass and yoke + teeth + winding + carcass [14]

Some results are presented in table I, with an experimental comparison.

TABLE I : RESONANCE FREQUENCIES (Hz) FOR EACH MODE

\begin{tabular}{|c|c|c|c|c|c|}
\hline $\begin{array}{c}\mathrm{N}^{\circ} \\
\text { mode }\end{array}$ & $\begin{array}{c}\begin{array}{c}\text { Analytical } \\
\text { model }\end{array} \\
\end{array}$ & F.E.M. & $\begin{array}{c}\mathrm{N}^{\circ} \\
\text { mode }\end{array}$ & $\begin{array}{c}\text { Analytical } \\
\text { model }\end{array}$ & Experimental \\
\hline 0 & 3063 & 3151 & 0 & 2736 & $\begin{array}{l}2855 \\
(1.46)\end{array}$ \\
\hline 2 & 243 & 268 & 2 & 308 & $\begin{array}{l}376(3.32) \\
416(3.22)\end{array}$ \\
\hline 3 & 688 & 732 & 3 & 871 & $\begin{array}{l}1004 \\
1140(1.74)\end{array}$ \\
\hline 4 & 1319 & 1349 & 4 & 1670 & $\begin{array}{l}1720(1.31) \\
1968(2.44)\end{array}$ \\
\hline 5 & 2134 & 2078 & 5 & 2702 & $\begin{array}{l}2870(1.54) \\
2944(1.46)\end{array}$ \\
\hline
\end{tabular}

Resonance frequencies of the stator have been obtained by impact testing measurements, realized thanks to the impact test method. The comparison of the results with the analytical model are very satisfactory.

Let us note that the damping coefficient $\xi_{a}$ cannot be given theoretically. However, JORDAN [4] considers that for a synchronous machine, it stands between 0,01 and 0,04 . The total vibratory spectrum obtained by our analytical model is presented above (figure 5).

The simulation results agree well with the theory. In addition, the proximity of the frequency of excitation mode 
0 with the frequency of the resonant mode 0 (at $2844 \mathrm{~Hz}$ ) explains the vibration peak located around $2900 \mathrm{~Hz}$. However let us point out that precautions must be taken when analyzing the results.

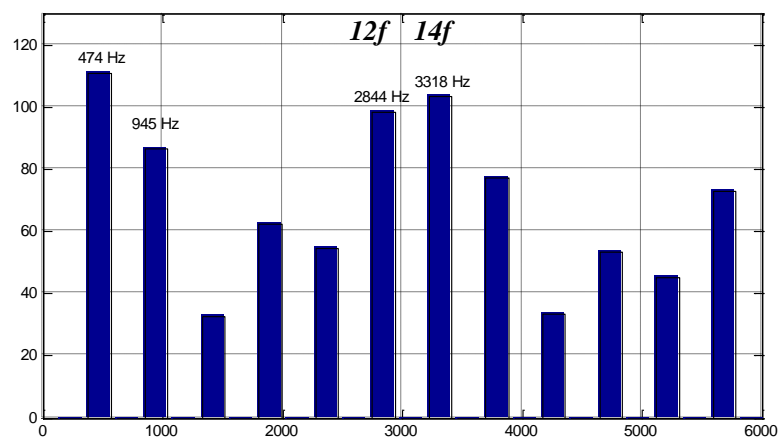

Figure 5. Total analytical vibratory spectrum with $3555 \mathrm{rpm}$

TABle II : Main Characteristics OF THE MACHINE

\begin{tabular}{cc}
\hline \hline Speed & $3555 \mathrm{rpm}$ \\
\hline Frequency of the supply $\mathrm{f}_{\mathrm{r}}$ & 237 \\
\hline Rotational frequency $\mathrm{f}_{\text {rot }}$ & $237 / \mathrm{p}$ \\
\hline $\begin{array}{c}\text { Frequencies of components of } \\
\text { forces (multiple of } 2 \mathrm{f})\end{array}$ & $\mathrm{h} .237$ \\
$(\mathrm{~h}=2,4,6 \ldots)$
\end{tabular}

The model giving the induction values is not perfect (the saturation phenomenon is neglected) and the formulae of TIMAR [3] giving the vibrations are also approximated. What is of interest is to determine the frequency of the main peaks and to be able to range their amplitudes.

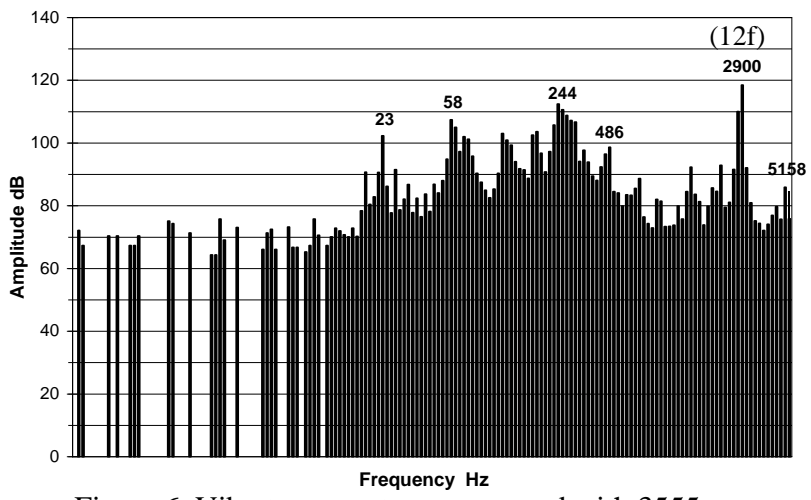

Figure 6. Vibratory spectrum measured with $3555 \mathrm{rpm}$ with $1 / 12$ of octave.

In order to study the vibrations generated by the operating conditions, an accelerometer is positioned on the frame of the machine. It measures the deformations of the frame. The vibratory spectrum gives lines identical to those obtained by the noise measurement; it displays a dominant line situated at $2900 \mathrm{~Hz}$, that corresponds to the theoretical excitation mode 0 predicted at $2844 \mathrm{~Hz}$ (Figure 6).

\section{3) Acoustic model}

Acoustic intensity $I(x)$ can be written as a function of the frequency, the amplitude of vibrations, the mode order and the stator surface [5], [9] :

$$
I(x)=\frac{\sigma 8200 f_{r}^{2} Y_{m d}^{2} S_{e}}{4 \pi x^{2}(2 m+1)}
$$

The coefficient $\sigma$ is called factor of radiation. It represents the capacity of a machine to be a good sound generator and can be calculated through two different ways according to whether one assumes the machine to be a sphere or a cylinder. $\sigma$ is a factor which varies with $\lambda$ (wavelength) and the diameter of the machine. It also depends on the mode shape [3]:

$$
\sigma=f\left(\pi \frac{D}{\lambda}\right), \quad \lambda=\frac{c}{f_{r}}
$$

$\mathrm{c}:$ Travelling speed of sound $(344 \mathrm{~m} / \mathrm{s}) ; f_{r}$ : Vibration frequency.

It appears that $I(x)$ is inversely proportional to the order of the mode, in addition the acoustic intensity is proportional to the square of the vibration amplitude. In general, we define $I$ and $W$ in decibels. We thus define the levels of acoustic pressure, acoustic intensity and sound power as follows:

$$
L_{p}=20 \log \left(\frac{P}{P}\right), \quad L_{i}=10 \log \left(\frac{I}{I_{0}}\right), \quad L_{w}=10 \log \left(\frac{W}{W_{0}}\right)
$$
with :

$$
P=20 \mu \mathrm{Pa}, \quad I_{0}=10^{-12} \mathrm{~W} / \mathrm{m}^{2}, \quad W_{0}=10^{-12} \mathrm{~W}
$$

The spectrum of the total noise obtained by our analytical model is presented below (figure 7).

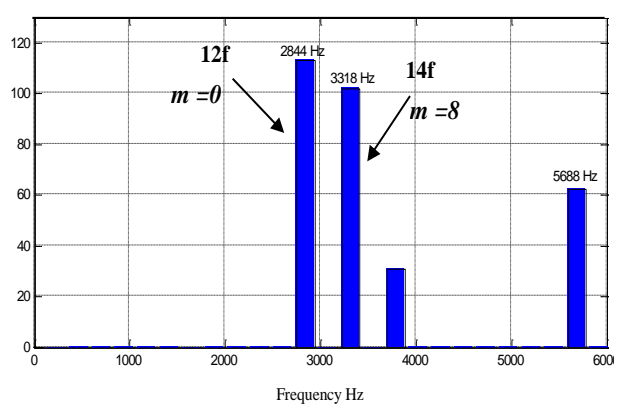

Figure 7. Spectrum of the noise of the simulated P.M.S.M.

Figure 8 presents the measured acoustic noise spectrum at the same speed $(3555 \mathrm{rpm})$. Lines are located at the same frequencies as in the vibration spectrum. 


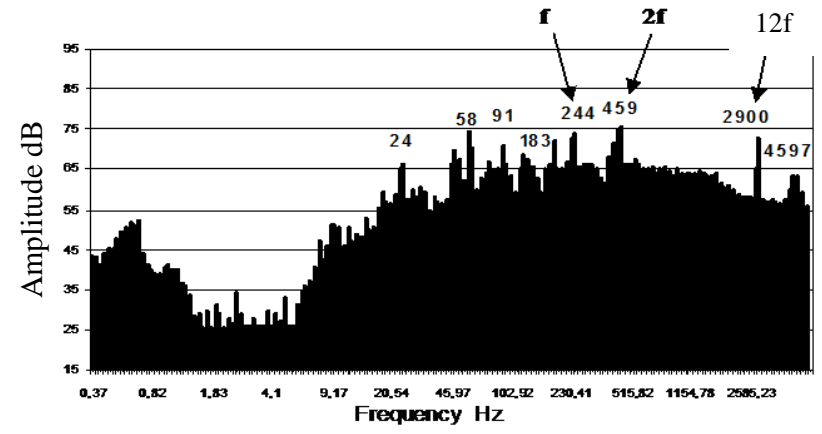

Figure 8. Spectrum of the noise of P.M.SM measured with $3555 \mathrm{rpm}$ (1/12 octave)

The first line determined by measurements is located at $2900 \mathrm{~Hz}$ (12f). In theory, the harmonic of teeth (12f) is located at $2844 \mathrm{~Hz}$.

The lines at low frequencies (between $24 \mathrm{~Hz}$ and 459 $\mathrm{Hz}$ ) are not found in theory, because they are mainly related to the background noise. They are not generated by the P.M.S.M., but by the driving motor and the ventilator (Figure 9).

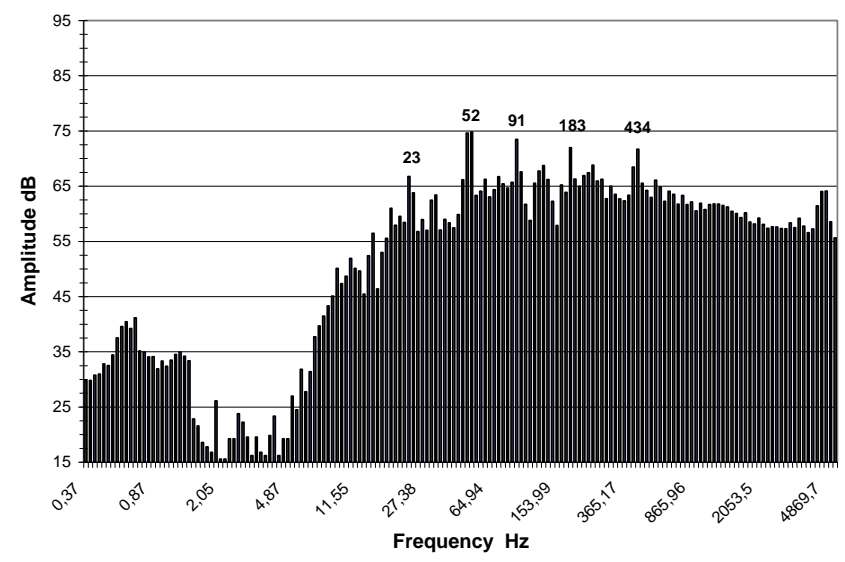

Figure 9. Spectrum of the noise of driving motor \& ventilator measured with $3555 \mathrm{rpm}$ (1/12 octave)

After this comparison, the permanent magnet synchronous machine was tested at various speeds, that allowed us to highlight a particularly dangerous speed. Moreover, some results are over-estimated but the quality of those is respected (Figure 10). In spite of the inaccuracies, major lines appear, which is of primary importance in view of noise reduction.

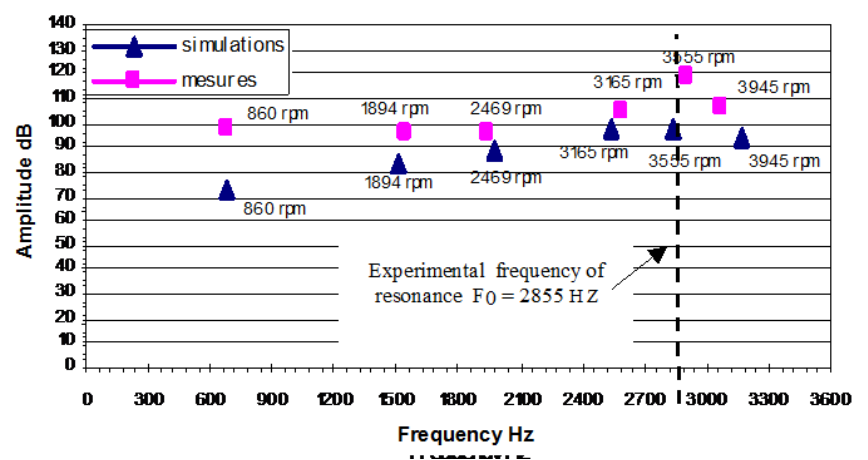

Figure 10. Level of the $12^{\text {th }}$ harmonic vs. rotation speed Vibratory comparisons
To know which lines to reduce does not require to know its amplitude precisely. Its frequency, on the other hand, must be well given. Lastly, taking into account the complexity of the studied phenomena and the many steps of calculations making it possible to lead to the results, the latter seem very satisfactory.

\section{SCREENING ANALYSIS}

Once the different models finalized and assembled into a single "coupled model", it becomes possible to study the variations of the main variables representing the vibration sources. This is achieved by the building of response surfaces, and by the launching of optimizations. The privileged tool employed is the Experimental Design Method [15], [16].

First of all, a sensibility analysis using the global coupled model is described.

The overall audible noise produced by the synchronous machine stands as the studied variable (the response). An analytical relation linking the noise amplitude with five variation sources (the factors) has been established :

- $\quad$ the stator slot opening (lse);

- $\quad$ the height of the yoke $\left(\mathrm{h}_{\text {yoke }}\right)$;

- $\quad$ the opening of permanent magnet (alp) ;

- $\quad$ the width of the air-gap (e) ;

- $\quad$ the height of the permanent magnet $\left(\mathrm{h}_{\mathrm{mag}}\right)$.

A screening design [17] is calculated. It gives the ability to determine the influent factors, with respect to the response, inside the design space. This domain is implicitly defined by the intervals of variation, for the five factors (Table III).

TABLE III : INTERVALS OF VARIATION - SCREENING ANALYSIS

\begin{tabular}{ccc}
\hline \hline Factors & Lower bound & Upper bound \\
\hline lse & $\mathrm{L}_{\mathrm{se}} \min$ & $\mathrm{L}_{\mathrm{se}} \min +20 \%$ \\
\hline $\mathrm{h}_{\text {yoke }}$ & $\mathrm{h}_{\text {yoke }} \min$ & $\mathrm{h}_{\text {yoke }} \min +20 \%$ \\
\hline $\mathrm{alp}$ & $30^{\circ}$ & $32^{\circ}$ \\
\hline $\mathrm{e}$ & $\mathrm{e}_{\min }$ & $\mathrm{e}_{\min }+20 \%$ \\
\hline $\mathrm{h}_{\mathrm{mag}}$ & $10 \mathrm{~mm}$ & $12 \mathrm{~mm}$ \\
\hline \hline
\end{tabular}

The following figure (Figure 11) gives a representation of the influence of each factor on the noise.

Firstly, it shows that the opening of the permanent magnets (alp) is a very influential factor, since its variation from its middle value $\left(31^{\circ}\right)$ to its upper limit $\left(32^{\circ}\right)$ makes the noise increase by about $15 \mathrm{~dB}$.

The height of the yoke $\left(\mathrm{h}_{\text {yoke }}\right)$, the width of the air-gap (e) and the stator slot opening (lse) are also significant factors according to this figure, since they all exceed the two $95 \%$ significance levels. It means that the probability to declare these factor influential although they are not, is equal to $5 \%$. They all have a negative influence on the noise variations: their values have to be increased to reduce the noise amplitude.

The height of the magnets $\left(\mathrm{h}_{\text {mag }}\right)$ is not considered as an influent factor, if the same significance level is used. 


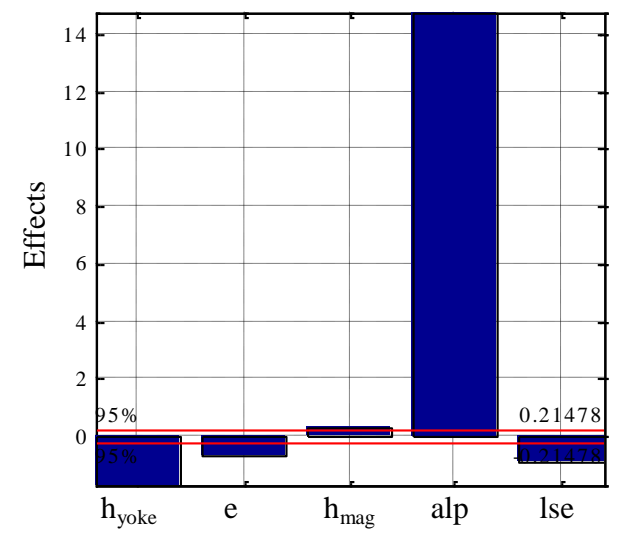

Figure 11. Factor influences on the noise amplitude

It is important to keep in mind that these conclusions only hold inside the design domain.

The previous results have been obtained for a fixed rotor speed (3000 rpm). Imposing different speeds do not change the relative influence of the factors. However, one can say that effect values increase for speeds around 3000 $\mathrm{rpm}$. This aspect will be confirmed by the following study.

\section{RESEARCH OF OPTIMAL CONDITIONS}

In a second stage, our purpose was to "model" the part of the conception domain in which the global audible noise produced by the P.M.S.M. was smaller than a predefined limit: $80 \mathrm{~dB}$ was considered as the maximal admissible noise intensity. This frontier for the noise - the response has been computed with respect the same factors except the height of the permanent magnet $\left(\mathrm{h}_{\mathrm{mag}}\right)$ and in addition, the motor speed $(\mathrm{N})$.

These factors have been selected thanks to screening analyses realized with the complete coupled model. Their intervals of variation are given by Table IV.

TABLE IV : INTERVALS OF VARIATION - MODELING STAGE

\begin{tabular}{ccc}
\hline \hline Factors & Lower bound & Upper bound \\
\hline 1 se & $\mathrm{L}_{\text {se }} \min$ & $\mathrm{L}_{\text {se }} \min +20 \%$ \\
\hline $\mathrm{h}_{\text {yoke }}$ & $\mathrm{h}_{\text {yoke }} \min$ & $\mathrm{h}_{\text {yoke }} \min +50 \%$ \\
\hline $\mathrm{alp}$ & $26^{\circ}$ & $34^{\circ}$ \\
\hline $\mathrm{e}$ & $\mathrm{e}_{\min }$ & $\mathrm{e}_{\min }+50 \%$ \\
\hline $\mathrm{N}$ & $3500 \mathrm{rpm}$ & $4500 \mathrm{rpm}$ \\
\hline \hline
\end{tabular}

Since we want to have a good description of the variations of the noise with respect to the five factors, it is necessary to increase the number of the different levels taken by each factor. Considering 5 levels is in general enough. Such a configuration leads to $5^{5}=3125$ experiments with the use of a grid design - that is a multilevel full factorial design. This number of evaluations of the coupled model is relatively large, and it can be interesting to take advantage of the new "trellis" deigns [17].

Trellis designs can be described as multi-level fractional grid design. They are build from fractional 2level factorial designs judiciously superposed (Figure 12). For this reason, under important hypotheses, they keep their interesting mathematical characteristics, such as for instance the orthogonality property.

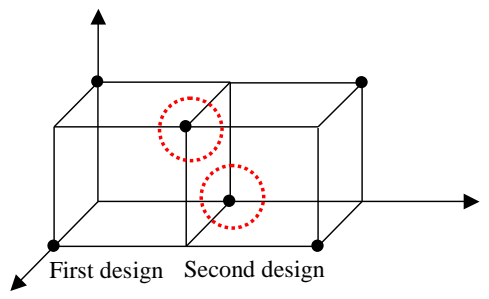

Figure 12 : Example of experiment sharing between two fractional designs $\left(2^{3-1}\right)$

When 5 factors are present, it is possible to use the 2level fractional factorial design defined as $2^{5-2}$, that is the quarter $\left(2^{2}=4\right)$ of the corresponding full factorial design $2^{5}$. When this design is used to build the trellis design, it leads to definition of a 5-level incomplete grid, with only 795 experiments - instead of 3125 with a complete grid. It takes approximately 16 hours to compute this trellis design on a PC.

Instead of using the 795 values of noise directly, we have exploited the interesting relative location of the experiments inside the design domain: an iterative procedure has been applied to estimate the noise values for each of the $3125-795=2330$ initially non-evaluated experiments. It has been shown that the overall error made for these 2330 interpolations, realized thanks to the 795 initial experiments, is lower than $0.8 \%$.

The different results that follow are deduced from the 795 first experimental points mixed with the estimated ones.

It quickly appeared that the opening of the permanent magnets (alp) and the motor speed (N) were the two most influential variables over the noise production. The following response surface shows the corresponding variations, as shown in figure 13.

It is very clear that the noise is strongly reduced when the permanent magnet area - in fact the corresponding angular opening - is equal to $30^{\circ}$. This result is confirmed by practical considerations.

The rotor speed has also a neat influence over the noise production. A resonance phenomenon is visible near the speed value $3500 \mathrm{rpm}$, whatever the factor alp values.

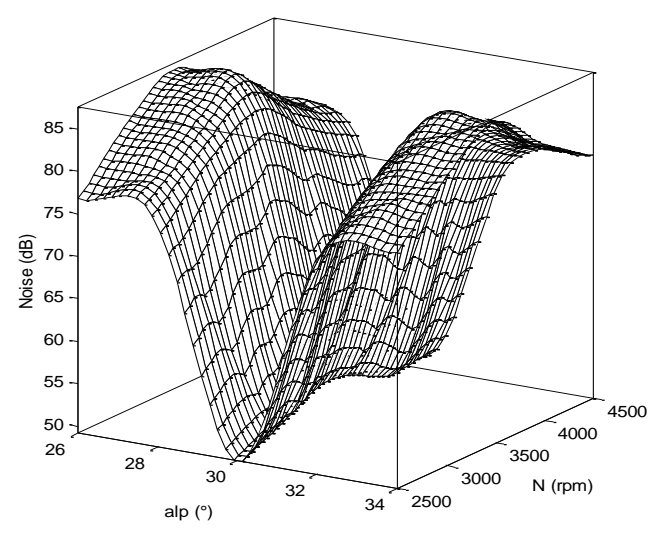

Figure 13. Noise variations vs. 'alp' and 'N' 
The influence of the three other factors are relatively small in comparison. However, we can notice that the decrease of $\mathrm{h}_{\text {yoke }}$ leads to move the resonance point towards lower rotation speed values.

The $80 \mathrm{~dB}$ limit can be graphically represented with respect to alp, $\mathrm{N}$ and $\mathrm{h}_{\mathrm{yoke}}$, thanks to iso-value surfaces (figure 14).

Two iso-value surfaces are represented: one showing the noise equal to $80 \mathrm{~dB}$, and the other to $84 \mathrm{~dB}$. The graphic is nearly symmetrical: $30^{\circ}$ standing as the central value for the magnet opening (alp). Then, the admissible sub-space of the conception domain is modeled by the zone delimited by the two central $80 \mathrm{~dB}$ surfaces. This indicates that it is always possible to conceive a P.M.S.M. generating a noise lower than $80 \mathrm{~dB}$, provided that the magnet opening is chosen between $28.5^{\circ}$ and $31.5^{\circ}$. This interval can be extended for particular rotor speeds greater than $4000 \mathrm{rpm}$ or lower than $2700 \mathrm{rpm}$.

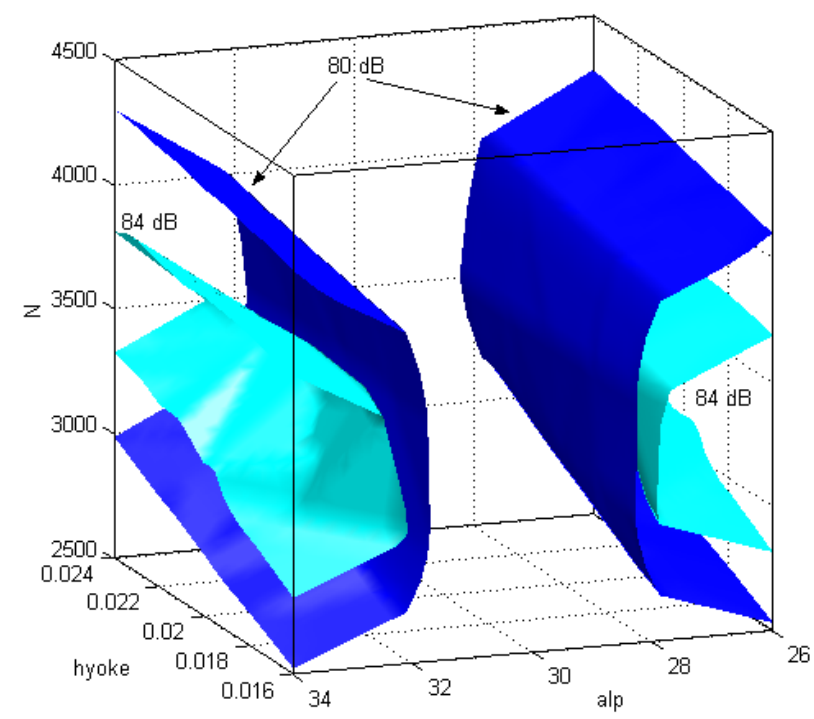

Figure 14. Noise iso-value surfaces ( 80 and $84 \mathrm{~dB}$ ) versus ' $\mathrm{N}$ ', ' $\mathrm{h}_{\text {yoke }}$ ' and 'alp'

\section{CONCLUSION}

The purpose of this work is to present some results obtained from the exploitation of a complete coupled model of a permanent magnet synchronous machine. Different multi-physical aspects are considered: electromagnetic, mechanic and acoustic phenomena are taken into account thanks to a single analytical model.

The Experimental Design Method is the privileged tool used to make the complex relationships between the main variables appear.

The first study - a screening analysis - shows that, whatever the rotor speed considered, the angular opening is a very influential factor: the particular value $30^{\circ}$ is certainly the best choice. It is more difficult to set the other factors, since the rotor speed interacts with them. However, the height of the permanent magnets is declared non significant in term of acoustic noise.

The second study is designed to work on more precise data. For that purpose, a trellis design with five levels per factor and only 795 experiments, is computed. The advantageous properties of this type of design allow the subsequent evaluations of 2330 other points, with an excellent accuracy, leading to practical design choices for lowering the limited noise.

\section{REFERENCES}

[1] M. Gabsi, 'Conception de machines spéciales et de leurs alimentations. Réduction $\mathrm{du}$ bruit d'origine électromagnétique', Habilitation à diriger des recherches, Juillet 1999.

[2] Timochenko S., "Théorie des vibrations", Librairie Polytechnique, CH Beranger, 1939.

[3] Timar P.L., "Noise and Vibration of Electrical Machines", Elsevier, 1989.

[4] Jordan. H., "Electric motor silencer - Formation and elimination of the noises in the electric motors" W.Giradet-Essen Editor 1950.

[5] S.J. Jang, 'Low-noise electrical motors', Clarendon Press Oxford, 1981.

[6] Boules N., "Prediction of no-load flux density distribution in permanent magnet machines", IEEE Transactions on Industry Applications, Vol. IA 21, N4, 1985.

[7] Ree J.D.L., Boules N., "Torque production in permanent magnet synchronous motors", IEEE Industry Application Soc. Conf. Record, Vol87, 1987, pp15-20.

[8] Zhu Z.Q., Howe D., "Instantaneous magnetic field distribution in brushless permanent magnet DC motors. Part III : Effect of stator slotting Field" - IEEE Transaction on Magnetics, Vol.29 N¹ January1993- pp.143-151.

[9] R.Corton, 'Bruit magnétique des machines asynchrones, procédure de réduction passive et active', thèse, 2000, Université d'Artois - France.

[10] A.Ait-hammouda, M.Hecquet, M.Goueygou, P.Brochet, A.Randria. 'Analytical approach to study noise and vibration of a synchronous permanent magnet machine', ISEF'2003, Maribor, 18 Sept. 2003, CD.

[11] OPERA_2D, Reference Manual, VECTOR FIELDS, http://www.vector-field.co.uk.

[12] Breahna R., Viarouge P., "Space and time harmonics interactions in synchronous machines", 1999, proceedings of Electrimacs - pp 45-50.

[13] Brüel \& Kjaer, PULSE system : modal test consultant, http://www.bksv.com.

[14] Verma S.P., Wen Li, "Experimental procedures for measurement of vibration and radiated acoustic noise of electrical machines", Power System Research Group 2002, p432, ICEM 2002.

[15] J.J. Droesbeke, J. Fine, G. Saporta, 'Plans d'expériences Applications à l'entreprise'

[16] J. Goupy, ' La Méthode des plans d'Expériences', Dunod, Paris, 1988

[17] Vivier S., "Stratégies d'optimisation par plans d'expériences et Application aux dispositifs électrotechniques modélisés par éléments finis", Thèse de doctorat, Université des Sciences et Techniques de Lille, July 2002. 